\title{
INSTRUÇÕES AOS COLABORADORES

\section{APRESENTAÇÃO}

Criada em 1944, a Revista Brasileira de Estudos Pedagógicos (Rbep) é um periódico editado em formato impresso e eletrônico e tem periodicidade quadrimestral. Publica artigos inéditos de natureza técnicocientífica, resultantes de estudos e pesquisas que contribuam para o desenvolvimento do conhecimento educacional e que possam oferecer subsídios às decisões políticas na área. Seu público-leitor é formado por professores, pesquisadores e alunos de graduação e pós-graduação, técnicos e gestores da área de educação.

A Rbep compõe-se das seguintes seções:

- "Estudos" - Publica artigos inéditos, resultantes de estudos, pesquisas, debates e experiências relacionadas com educação e áreas afins.

- "Resenhas" - Analisa criticamente os lançamentos recentes na área.

A Rbep acha-se aberta a sugestões e à indicação de trabalhos e contribuições que façam avançar o conhecimento e estimulem a reflexão sobre a educação. 


\section{NORMAS EDITORIAIS}

Os artigos deverão ser encaminhados exclusivamente mediante o Sistema Eletrônico de Editoração de Revistas (Seer), cujas instruções se encontram disponíveis no site www.rbep.inep.gov.br, no qual o autor poderá acompanhar o andamento do trabalho.

Os artigos deverão ter entre 24 e 48 laudas e poderão ser redigidos em português ou espanhol e ser encaminhados em qualquer época.

Os artigos são avaliados por consultores ad hoc de reconhecida competência nos temas abordados, diversificados regional e institucionalmente, com parecer final da editoria científica. Os artigos são encaminhados sem identificação de autoria, e o prazo para sua avaliação é de três meses.

Os aspectos considerados na avaliação dos artigos são os seguintes:

- Questões referentes à forma: os aspectos gramaticais e estilísticos.

- Questões referentes ao conteúdo: a importância do tema abordado, a definição da questão principal, a estrutura, o desenvolvimento e a conclusão do trabalho.

Os pareceres envolvem três tipos de julgamento:

- Aprovado - o artigo é programado para publicação.

- Aprovado com modificações - são solicitados ao autor ajustes ou reformulações no artigo, com o envio de nova versão para avaliação final.

- Não aprovado - o artigo é recusado.

A aprovação final dos artigos é de responsabilidade da Editoria Científica da Rbep.

$\mathrm{O}$ atendimento das condições especificadas nas "Normas gerais para a apresentação de originais", é imprescindível para a publicação do artigo.

A aceitação do artigo implica automaticamente a cessão dos direitos autorais ao Inep, relativos ao trabalho.

$\mathrm{Na}$ fase de revisão, os originais poderão sofrer alterações, respeitando-se o estilo e as opiniões dos autores, com vista a manter a qualidade editorial da revista.

Os autores receberão três exemplares da revista pelo trabalho publicado.

Endereço eletrônico para o envio das propostas

http://www.rbep.inep.gov.br 


\section{NORMAS GERAIS PARA A APRESENTAÇÃO DE ORIGINAIS}

A fim de facilitar o tratamento e a disseminação dos trabalhos enviados para publicação nos periódicos do Inep, apresentamos algumas normas técnicas para o estabelecimento de padrões de estilo e apresentação dos textos.

\section{Mídia}

Os originais deverão ser encaminhados pelo endereço da revista www.rbep.inep.gov.br, em arquivo formato Word, digitados em espaço 1,5, com a extensão mínima de 24 laudas e máxima de 48 laudas de 1.400 caracteres, com espaço, cada lauda.

\section{Fonte}

A fonte utilizada deverá ser a Times New Roman, sendo em corpo 12 para o texto, em corpo 10 para as citações destacadas e em corpo 8 para as notas de rodapé.

\section{Ilustrações}

As ilustrações deverão ser limitadas à compreensão do texto, possuir resolução a partir de 300 dpi e vir acompanhadas das fontes e de título que permita compreender o significado dos dados reunidos.

Somente serão aceitos gráficos, quadros e tabelas (de preferência, em Excel e de acordo com as normas de apresentação tabular do IBGE), fotografias, desenhos e mapas, se em condições de fácil reprodução.

\section{Título}

O título do artigo deve ser breve, específico e descritivo, contendo as palavras representativas do seu conteúdo, e vir, também, traduzido para o inglês.

\section{Resumos}

Os artigos enviados para a Rbep deverão ser acompanhados, obrigatoriamente, de resumos informativos em português e inglês, com 10 linhas no máximo, os quais devem conter informações qualitativas e quantitativas e dados essenciais, tais como:

Descrição - Indica o tipo de artigo a ser analisado (artigo original, de revisão, estudo de caso).

Objetivo - Descreve as razões pelas quais o trabalho foi realizado, o que se buscou demonstrar e a natureza do problema tratado.

Metodologia - Descreve a abordagem teórica e/ou metodológica empregada, as principais técnicas utilizadas, indica as fontes dos dados e o modo como estes foram utilizados, quais os conceitos desenvolvidos e como foram analisadas as variáveis. 
Resultados - Descrevem sucintamente as descobertas significativas e importantes da pesquisa.

Conclusão - Descreve as implicações dos resultados, especialmente como se relacionam aos objetivos do trabalho, e pode incluir recomendações, aplicações, sugestões e avaliações.

\section{Palavras-chave}

Os artigos enviados à Rbep devem conter palavras-chave referentes ao seu conteúdo, escolhidas em vocabulário controlado: Thesaurus Brasileiro de Educação - disponível em www.inep.gov.br/pesquisa/thesaurus

\section{Citações}

As citações com até três linhas devem vir entre aspas, dentro do parágrafo, acompanhadas por uma chamada entre parênteses para o autor, o ano e o número da página da publicação. Ex:

Segundo Soares (2000, p. 234) "uma nova relação entre ensino, pesquisa, aprendizagem e avaliação processual" exige novas posturas pedagógicas e metodológicas.

As citações com mais de três linhas devem ser destacadas com recuo, sem aspas, em corpo 10, redondo. Ex:

[...] os professores têm sido desafiados a se desprenderem de práticas mais tradicionais e a investirem em práticas pedagógicas reflexivas, criadoras, e com especial significado para suas próprias práticas e para o movimento educacional que estão instalando em suas classes, qualificando o debate e as discussões em sala de aula, o que materializa, mesmo que indiretamente, uma estratégia de formação continuada dos docentes. (Soares; Oliveira, 2003, p. 9).

A referência bibliográfica completa da citação virá em lista única ao final do artigo. A exatidão e a adequação das citações e referências a trabalhos consultados e mencionados no texto são de responsabilidade do autor.

\section{Notas}

As notas de rodapé devem ser evitadas. Quando necessárias, que tenham a finalidade de: observações complementares; realizar remissões internas e externas; introduzir uma citação de reforço e fornecer a tradução de um texto. As indicações das fontes bibliográficas deverão ser feitas no texto.

\section{Referências bibliográficas}

As referências bibliográficas devem constituir uma lista única no final do artigo, em ordem alfabética por sobrenome do autor; devem ser 
completas e elaboradas de acordo com as normas da Associação Brasileira de Normas Técnicas (ABNT) - NBR 6.023.

Quando se tratar de obra consultada on-line, é necessário indicar o endereço eletrônico e a data em que foi acessada; se a obra estiver em suporte eletrônico (DVD, CD-ROM), essa informação também deve constar após a sua identificação.

Livros (um autor)

FLORIANI, José Valdir. Professor e pesquisador: exemplificação apoiada na Matemática. 2. ed. Blumenau: Furb, 2000. 142 p. (Programa Publicações de Apoio à Formação Inicial e Continuada de Professores).

Livros (dois autores)

DAMIÃO, Regina Toledo; HENRIQUES, Antonio. Curso de direito jurídico. São Paulo: Atlas, 1995

Capítulos de livro

REGO, L. L. B. O desenvolvimento cognitivo e a prontidão para a alfabetização. In: CARRARO, T. N. (Org.). Aprender pensando. 6. ed. Petrópolis: Vozes, 1991. p. 31-40.

Artigos de periódico

GOROVITZ, Matheus. Da educação do juízo de gosto. Revista Brasileira de Estudos Pedagógicos, Brasília, v. 79, n. 193, p. 86-94, set./dez. 1998.

Teses e dissertações

ARAÚJO, U. A. M. Máscaras inteiriças tukúna. 1985. 102 f. Dissertação (Mestrado em Ciências Sociais) - Fundação Escola de Sociologia e Política de São Paulo, São Paulo, 1986.

\section{Artigos de jornal com autor identificado}

LEAL, L. N. MP fiscaliza com autonomia total. Jornal do Brasil, Rio de Janeiro, p. 3, 25 abr. 1999.

Artigos de jornal sem identificação de autor

ARRANJO tributário. Diário do Nordeste Online, Fortaleza, 27 nov. 1998. Disponível em: <http://www.diariodonordeste.com.br>. Acesso em: 28 nov. 1998. 
BRASIL. Lei no 9.887, de 7 de dezembro de 1999. Altera a legislação tributária federal. Diário Oficial [da] República Federativa do Brasil, Brasília, DF, 8 dez. 1999. Disponível em: <http://www.in.gov.nbr/ mp_leis/leis_texto.asp?ld=LEI\%209887>. Acesso em: 22 dez. 1999.

\section{Constituição Federal}

BRASIL. Constituição (1988). Emenda constitucional no 9, de 9 de novembro de 1995. Lex: legislação federal e marginália, São Paulo, v. 59, p. 1996, out./dez. 1995.

Trabalhos publicados em Anais de Congresso

GUNCHO, M. R. A educação a distância e a biblioteca universitária. In: SEMINÁRIO DE BIBLIOTECAS UNIVERSITÁRIAS, 10., 1998. Fortaleza. Anais... Fortaleza: Tec Treina, 1998. 1 CD-ROM.

\section{Siglas}

$\mathrm{Na}$ primeira citação, as siglas devem vir entre parênteses, imediatamente após o nome, por extenso, das entidades ou coisas que representam.

Ex.: Centro de Informação e Biblioteca em Educação (Cibec).

\section{Destaques}

O uso de negrito deve ficar restrito aos títulos e intertítulos; o de itálico, apenas para destacar conceitos ou grifar palavras em língua estrangeira.

\section{Reedição}

Textos para reedição deverão ser apresentados na forma originalmente publicada, de modo a assegurar a indicação da fonte primitiva. No caso de tradução, anexar cópia da folha de rosto da publicação original.

\section{Currículo-síntese}

Devem constar do trabalho informações quanto à titulação acadêmica do autor e respectiva instituição; área de estudos e linha de pesquisa; atividades que desempenha; instituição a que está vinculado; endereços residencial, profissional e eletrônico completos.

\section{Somente serão aceitos os trabalhos que preencherem as condições} citadas. 

Esta obra foi impressa no Rio de Janeiro,

em 2012.

Capa impressa em papel cartão supremo 250g e miolo em papel off-set $75 \mathrm{~g}$.

Texto composto em Egyptian505 Lt BT corpo 10. 